\title{
Home-based exercises during the COVID-19 quarantine situation for office workers: A commentary
}

\author{
Ardalan Shariat ${ }^{\mathrm{a}, *}$, Joshua A. Cleland ${ }^{\mathrm{b}}$ and Azadeh Hakakzadeh ${ }^{\mathrm{a}}$ \\ ${ }^{a}$ Sports Medicine Research Center, Neuroscience Institute, Tehran University of Medical Sciences, Tehran, Iran \\ ${ }^{\mathrm{b}}$ Department of Public Health and Community Medicine, Tufts University School of Medicine, Boston, MA, USA
}

Received 23 April 2020

Accepted 25 April 2020

\begin{abstract}
Staying at home for the prevention of COVID-19 is an accepted fact. Office workers are a group of people, who had to wake up early in the morning and at least had a fixed pattern of sleeping and working. In this situation, complaints about the neck, shoulder and lower back tend to increase and this is a good time to learn and perform some practical exercises at home. This commentary presents possible home-based exercises for prevention of musculoskeletal disorders among office workers, following the guidelines prepared by the American College of Sports Medicine.
\end{abstract}

The coronavirus (COVID-19) pandemic makes it challenging to maintain a physically active lifestyle. COVID-19 is transmitted by groups of people in close proximity to one another. Therefore, guidance indicates that we should avoid public gatherings and keep a social distance of at least 6 feet from other people. This means that exercising in public gyms is challenging as many people frequent the same space every day and being able to maintain an appropriate social distance from others is not possible [1].

In a quarantine situation, you are strongly suggested to stay at home and keep distance from other people. What will happen? You will lose your normal physical activity routine, you will likely spend more time sitting on the sofa, watching television, and

\footnotetext{
*Address for correspondence: Dr. Ardalan Shariat, Sports Medicine Research Center, Neuroscience Institute, Tehran University of Medical Sciences, Tehran, Iran. Tel.: +982188630227; E-mail: a-shariat@razi.tums.ac.ir.
}

eating junk food. Your weight will perhaps increase, flexibility of your joints will decrease and musculoskeletal symptoms will appear slowly. Multiple risk factors, such as smoking, diabetes, hypertension and obesity will boost this critical situation. Regular home-based exercises could be useful to keep you active and prevent some of those issues and assist in keeping you fit and healthy $[2,3]$.

For health benefits, a combination of aerobic exercises and strength training are suggested for different age groups. The American College of Sports Medicine (ACSM) has suggested performing 2 sessions of resistance training/week and 150-300 minutes of aerobic exercise training with a moderate level of intensity/week. The duration could be divided into short periods, such as $2,5,10$ or 20 minute increments [4-8].

Resistance training could include doing things such as squats using your body weight, push-ups against the wall, sit to stand exercises, single leg 
step-ups on stairs, and also shoulder lateral raises using bottles of water as resistance. Aerobic exercises could include dancing, jumping rope, use of a cardio machine, or walking around the house $[8,9]$.

The main purpose of those exercises is to keep you active and healthy during the quarantine situation.

We believe that this situation will be resolved soon, but during this time, it is necessary to stay at home, stay fit and improve our immune system by performing a combination of resistance and aerobic exercises.

\section{Conflict of interest}

None to report.

\section{References}

[1] Holmes EA, O'Connor RC, Perry VH, Tracey I, et al. Multidisciplinary research priorities for the COVID-19 pandemic: a call for action for mental health science. The Lancet Psychiatry. 2020, [Epub ahead of print].
[2] Jiménez-Pavón D, Carbonell-Baeza A, Lavie CJ. Physical exercise as therapy to fight against the mental and physical consequences of COVID-19 quarantine: Special focus in older people. Prog Cardiovasc Dis. 2020, [Epub ahead of print].

[3] Halabchi F, Ahmadinejad Z, Selk-Ghaffari M. COVID-19 Epidemic: Exercise or Not to Exercise; That is the Question! Asia J Sport Med. 2020:11(1):e102630.

[4] Anastasio AT. Discrete isometric exercise for the individual with time and facility constraints. ACSM's Health \& Fitness Journal. 2020;24(2):22-30.

[5] Miguel H. The use of different models of physical exercises performed at home during the COVID-19 pandemic. Inter Amer J Med Healt. 2020;3.

[6] Bushman BA. Exercise for prevention of chronic diseases. ACSM's Health \& Fitness Journal. 2020;24(1):5-10.

[7] Gilat R, Cole BJ. COVID-19, Medicine, and Sports. Arthrosc Sports Med Rehabil. 2020, [Epub ahead of print].

[8] Shariat A, Lam ETC, Kargarfard M, Tamrin SBM, Danaee $M$. The application of a feasible exercise training program in the office setting. Work. 2017;56(3),421-428.

[9] Barros FC, Cabral AM, Moreira R de FC, Sato T de O. Does adherence to workplace-based exercises alter physical capacity, pain intensity and productivity? Euro J Physio. 2019;21(2):83-90. 